\title{
A ambivalência do pensamento de José Leite Lopes sobre Desenvolvimento em "Ciência e Libertação"1
}

\author{
Alcides Eduardo dos Reis Peron ${ }^{2}$ \\ Tildo Furlan ${ }^{3}$
}

\begin{abstract}
Resumo: Dotado de uma exuberante biografia, José Leite Lopes viveu e protagonizou o processo de institucionalização da ciência no Brasil e nos países latino-americanos. Assim, o objetivo desse artigo é realizar uma breve investigação acerca do pensamento em Ciência, Tecnologia e Sociedade desenvolvido pelo físico, atentando para o momento em que as suas observações se aproximam das realizadas pelo PLACTS (Pensamento Latino Americano em Ciência, Tecnologia e Sociedade). Para tanto, exploraremos as principais características do PLACTS, destacando a essência do pensamento de Leite Lopes. A partir disso, nos debruçaremos sobre as perspectivas de Celso Furtado acerca do desenvolvimento subordinado e subdesenvolvimento para analisarmos as posições de Leite Lopes.
\end{abstract}

Palavras-Chave: José Leite Lopes; Pensamento Latino Americano em Ciência Tecnologia e Sociedade; Desenvolvimento

\section{The ambivalence of José Leite Lopes' thinking on development in the book "Ciência e Libertação"}

Abstract: Endowed with an exuberant biography, José Leite Lopes lived and starred in the process of institutionalization of science in Brazil and Latin American countries.

\footnotetext{
${ }^{1}$ Recebido em 03/05/18 e aprovado em 13/06/18.

${ }^{2}$ Doutor em Política Científica e Tecnológica pela Unicamp, pesquisador do Grupo de Análise de Políticas e Inovação DPCT-UNICAMP (GAPI) e do Grupo de Estudos em Tecnologias de Defesa e a Evolução do Pensamento Estratégico (GETED). E-mail: dudperon@gmail.com

${ }^{3}$ Doutorando pelo Departamento de Política Científica e Tecnológica da Unicamp. E-mail: tildo.furlan@hotmail.com
} 
Thus, the purpose of this article is to carry out a brief investigation about the thought in Science, Technology and Society developed by the physicist, considering the moment in which his observations are close to those realized by PLACTS (Latin American Thinking in Science, Technology and Society). To do so, we will explore the main characteristics of PLACTS, highlighting the essence of Leite Lopes' thinking. Based on this, we will focus on Celso Furtado's perspectives on subordinate development and underdevelopment to analyze Leite Lopes's positions.

Keywords: José Leite Lopes; Latin American Thinking in Science, Technology and Society; Development

\section{La ambivalencia del pensamiento de José Leite Lopes sobre Desarollo em "Ciência e Libertação"}

Resumen: Dotado de una exuberante biografía, José Leite Lopes vivió y protagonizó el proceso de institucionalización de la ciencia en Brasil y en los países latinoamericanos. El objetivo de este artículo es realizar una breve investigación acerca del pensamiento en Ciencia, Tecnología y Sociedad desarrollado por el físico, atentando para el momento en que sus observaciones se aproximan a las realizadas por el PLACTS (Pensamiento Latinoamericano en Ciencia, Tecnología y Sociedad). Para ello, exploraremos las principales características del PLACTS, destacando la esencia del pensamiento de Leite Lopes. A partir de eso, nos ocuparemos sobre las perspectivas de Celso Furtado acerca del desarrollo subordinado y subdesarrollo para analizar las posiciones de Leite Lopes.

Palavras-Clave: José Leite Lopes; Pensamiento Latinoamericano en Ciencia, Tecnología y Sociedad; desarrollo.

\section{Introdução}

Em seu livro "Ciência com Consciência", Edgar Morin (1982) se propõe a discutir o caráter ambivalente da ciência, a qual em sua gênese fundamenta-se como fenômeno libertador do pensamento humano, extirpando o obscurantismo e as formas de poder a ele relacionadas, e reposicionando a razão como centro das relações humanas. Contudo, observando-a em sua manifestação contemporânea após sua institucionalização como estandarte do moderno, Morin apresenta a sua faceta mais tenebrosa: uma cristalização das relações de poder e da ideologia de uma sociedade marcada por uma profunda divisão de classes. Travestida de razão 
libertadora, e justificada por um método sanitarizante de qualquer subjetivação política, a ciência e a razão positivista teriam sido responsáveis por diversas atrocidades do século $\mathrm{XX}$, como o desenvolvimento de armamento nuclear, segregação racial e a falência da bioética.

A Morin interessava, então, explicitar a importância do cientista em investigar a trajetória histórica da ciência e da tecnologia, compreendendo as suas determinações políticas, o que conferiria consciência à ciência, seja de seus limites éticos, seja dos seus efeitos sobre a sociedade. Nesse espírito é que os trabalhos de José Leite Lopes tomam forma, como uma tentativa de conferir importância política à trajetória e aos rumos da ciência e da tecnologia produzida no contexto econômico dos países subdesenvolvidos. De modo geral, Leite Lopes acreditava em um potencial emancipador da ciência para os países periféricos, o qual governaria um processo de desenvolvimento econômico fundamental para a supressão das mazelas inerentes ao capitalismo periférico.

Sem perder de vista as peculiaridades históricas que balizaram os rumos econômicos dos países periféricos para uma condição de subdesenvolvimento, e ciente das características específicas da política de ciência e tecnologia que orientaram o desenvolvimento econômico dos países centrais, Leite Lopes afirma a necessidade em proceder com um processo modernizador que confira maior atenção à produção independente e a autonomia da ciência nesses países. Escrevendo em meados da década de 60, e protagonista dos projetos que ajudaram a consolidar as atividades de pesquisa científica no Brasil durante o auge do período desenvolvimentista militar, o físico Leite Lopes faz coro com uma série de outros cientistas de sua época que buscavam atentar para a importância em se consolidar instituições e condições mínimas para o desenvolvimento científico no Brasil.

Aproximando-se de uma visão idealista da ciência, que em muito se refere aos imperativos "mertonianos" de universalidade e socialismo, Leite Lopes afirma que um povo permanece subdesenvolvido no momento em que é incapaz de obter, adotar 
e aplicar os resultados das pesquisas científicas em benefício próprio. De certo modo, ele fundamenta uma crítica ao processo de desenvolvimento econômico-industrial verificado no período, o qual, intensivo em exportações, e dependente dos resultados das pesquisas cientificas realizadas no exterior, conformaria uma industrialização dependente, e subjugada aos métodos modernos de exploração e dominação colonial (LOPES, 1969:14).

Dotado de uma exuberante biografia, Leite Lopes viveu e protagonizou o processo de institucionalização da ciência no mundo e principalmente nos países latino-americanos. O que torna o seu pensamento um importante objeto de estudos para compreensão dos atuais rumos da Política Científica e Tecnológica no Brasil.

Nesse sentido, em muito suas observações sobre o desenvolvimentocientífico brasileiroseaproximam do denominado Pensamento Latino Americano em Ciência, Tecnologia e Sociedade (PLACTS), que ao longo da segunda metade do século $\mathrm{XX}$ conformou uma poderosa crítica ao modelo de desenvolvimento industrial pela região. Logo, o objetivo desse artigo é realizar uma breve investigação acerca do pensamento em Ciência, Tecnologia e Sociedade desenvolvido pelo físico Leite Lopes, atentando para o momento em que as suas observações se aproximam das realizadas pelo PLACTS. Todavia, tanto no pensamento de Leite Lopes, como no do próprio PLACTS, há limitações sobre a relação entre Ciência e Desenvolvimento, os quais pretendemos também investigar ao longo desse artigo. Para tanto, exploraremos as principais características do PLACTS, a partir dos trabalhos de Renato Dagnino e Rafael Dias, buscando nesse processo, destacar as características do pensamento de Leite Lopes a respeito das ideias de desenvolvimento, liberdade e autonomia. A partir dessas considerações, nos debruçaremos sobre as perspectivas de Celso Furtado a respeito da relação entre desenvolvimento subordinado e subdesenvolvimento para estabelecer um parâmetro crítico acerca das posições de Leite Lopes. 


\section{A identidade entre o Pensamento de Leite Lopes e o PLACTS}

Um homem apaixonado. É assim que as pessoas mais próximas ligadas a Leite Lopes o definem. Suas paixões pela ciência e pela cultura fizeram com que se transformasse em um físico teórico de renome internacional, e também em uma pessoa bastante atenta aos problemas que a atividade científica enfrentava no Brasil.

O físico sempre lutou pela divulgação da ciência entre os jovens, de forma a estimular o surgimento de novos talentos no país. Foi um dos nomes mais importantes nos bastidores do processo de institucionalização da ciência no Brasil, por exemplo, ao desempenhar papel fundamental juntamente com César Lattes e com o apoio do Ministro João Alberto Lins de Barros, de Nelson Lins de Barros e de Henry British Lins de Barros, na criação, em janeiro de 1949, do Centro Brasileiro de Pesquisas Físicas (CBPF) e, em 1951, do Conselho Nacional de Desenvolvimento Científico e Tecnológico (CNPq). Participou, a convite de Darcy Ribeiro, da criação do Instituto de Física da Universidade de Brasília. Foi responsável ainda pela fundação da Escola Latino Americana de Física (ELAF) e do Centro Latino Americano de Física (CLAF).

Leite Lopes formou-se em Química Industrial na Escola de Engenharia de Pernambuco em 1939 e no ano seguinte mudou-se para o Rio de Janeiro para estudar Física na Faculdade Nacional de Filosofia. Em seguida recebeu uma bolsa para trabalhar na Universidade de São Paulo, onde assistiu aos cursos de professores como Gleb Wathagin e Mario Schenberg. Entre 1944 e 1945 doutorou-se na Universidade de Princeton sob a orientação de Wolfgang Pauli, ganhador do Prêmio Nobel de Física em 1945 e lá conheceu e manteve contato com Albert Einstein. Em seguida tornou-se catedrático em Física Teórica e Superior da Faculdade Nacional de Filosofia da Universidade do Brasil. Exilou-se do país em 1969, após ser aposentado compulsoriamente pelo AI 5 e retornou definitivamente ao Brasil somente em 1986 ao ser nomeado diretor científico do CBFP, quando Renato Archer assumiu a pasta do ministério de $C \& T$ no contexto da redemocratização. 
O trabalho de maior destaque de Leite Lopes é um artigo publicado em 1958 na revista Nuclear Physics, um periódico holandês, no qual o autor propõe a existência de um bóson vetorial neutro, uma partícula que somente foi detectada muitos anos mais tarde, o chamado z0. Esse trabalho é considerado precursor da unificação das teorias da interação eletromagnética e da teoria da interação fraca que hoje fazem parte da teoria da interação eletrofraca.

César Lattes destacava que embora Leite Lopes tenha sido o primeiro a sugerir tal unificação, "passo da maior importância no esforço do conhecimento da matéria fundamental", esse feito foi creditado a Steven Weinberg, Abdus Salam e Sheldon Glashow, lhes valendo em conjunto o Prêmio Nobel de Física de 1979. A descoberta de Leite Lopes foi brevemente mencionada no discurso na cerimônia de entrega do Prêmio, Weinberg apenas agradeceu o físico brasileiro, desculpando-se posteriormente ao dizer que não havia tomado conhecimento do artigo do brasileiro, o qual tinha sido publicado vinte anos antes (FREIRE JR e CLEMENTE, 2006).

$\mathrm{O}$ fato de Leite Lopes ter trabalhado com grandes nomes da ciência e ocupado postos de destaque em grandes centros universitários e de pesquisa ao redor do mundo, contribuiu para a sua formação não apenas como físico, mas também foi decisivo para moldar sua percepção sobre a relevância da ciência para o desenvolvimento dos países centrais e sobre a importância dos investimentos em ciência, na formação de cientistas, na institucionalização da atividade científica e na criação de infraestrutura para o seu funcionamento. Nesse sentido, concluiu que as trajetórias científicas e tecnológicas desses países eram elementos fundamentais na constituição do poder político, econômico e militar que detinham. Essa visão pode ser relacionada às ideias contidas no conhecido relatório Science The Endless Frontier de Vannevar Bush, cujo grande legado foi o fortalecimento da ideia de que os investimentos em pesquisa básica permitiriam descobertas que seriam objeto de pesquisas aplicadas, que gerariam inovações tecnológicas e que, por sua vez, gerariam desenvolvimento econômico (STOKES, 2005, p. 27). 
Segundo Stokes (2005) Bush resumiu suas proposições em duas afirmações: a) "a pesquisa básica é realizada sem se pensar em fins práticos"; b) "a pesquisa básica é precursora do progresso tecnológico". Dessa forma, se a pesquisa básica for feita livre de "considerações prematuras sobre sua utilidade", se transformará em um poderoso instrumento criador de progresso tecnológico à medida que o conhecimento gerado por ela se transformar em inovação tecnológica capaz de atender às demandas da sociedade, sejam elas econômicas, de defesa, de saúde, ou sociais. A ideia de Bush continha também, segundo Stokes, um elemento adicional: para Bush, quem investisse em ciência básica obteria um retorno equivalente em tecnologia à medida que os avanços da ciência fossem convertidos em inovações tecnológicas pelos processos de transferência de tecnologia (STOKES, 2005, p.19).

O envolvimento de Leite Lopes nos processos políticos de criação das grandes instituições científicas brasileiras é ao mesmo tempo fruto da experiência que adquiriu nos anos de trabalho no exterior e resultado de sua personalidade perspicaz e diplomática, que o permitia nutrir bons relacionamentos com atores da esfera política e também ser respeitado pela burocracia. Ao participar desses processos Leite Lopes percebeu importantes singularidades da política científica e tecnológica brasileira e também latinoamericana. Em suas palavras, o papel desempenhado pelo “[...] exercício da ciência é indispensável ao desenvolvimento econômico e este desenvolvimento é imprescindível à verdadeira independência e ao florescimento da cultura" (LOPES, 1958, p. 96).

Em 1963, quando discursou em Genebra na Conferência Internacional da ONU sobre as Aplicações da Ciência e da Tecnologia às Áreas menos Desenvolvidas, Leite Lopes defendeu que "países em via de desenvolvimento necessitam de uma tecnologia local". Por tecnologia local queria dizer:

Uma rede de institutos, em número conveniente, equipados com homens treinados e com equipamento para assessorar a indústria nacional, resolver os seus problemas técnicos, vários dos quais são específicos 
daquele país; institutos dotados de cientistas em contínuo trabalho de pesquisa pura e aplicada (LOPES, 1987, p. 142).

Essa visão se relaciona com a perspectiva progressista dos anos 1960 e 1970, segundo a qual o desenvolvimento econômico brasileiro só se concretizaria de forma plena com o estabelecimento de uma indústria de bens de capital nacional. Mais do que isso, tal perspectiva se identifica com a ideia de que o progresso científico e tecnológico nacional - a partir da institucionalização da ciência brasileira nos padrões e moldes internacionais, de forma que os projetos de pesquisa estivessem alinhados com os grandes temas da ciência mundial, respeitando os parâmetros da "Big Science" seria capaz de emancipar o Brasil da dominação política dos países centrais.

Um exemplo marcante do ativismo político de Leite Lopes, no sentido de inserir na agenda de pesquisa brasileira temas que estavam sendo pesquisados nos centros de excelência ao redor do mundo, foi a sua luta pela implantação de programas voltados à energia nuclear no Brasil. Importantes descobertas nessa área permitiriam o desenvolvimento da ciência básica de modo a dar origem a aplicações práticas. Para justificar a necessidade de pesquisas no campo da energia nuclear, Leite Lopes afirma, ao discorrer sobre o esgotamento das fontes energéticas tradicionais em meados do século $X X$, que "não é sem razão que os países altamente desenvolvidos, dotados, em abundância, de fontes clássicas de energia, buscam atualmente, em tempo acelerado, desenvolver os trabalhos de investigação científica e de aplicação relativos à energia atômica". Segundo sua visão, seria fundamental para os países em desenvolvimento considerar os efeitos positivos das descobertas nesse campo para a "sobrevivência do progresso industrial" (LOPES, 1958, p. 92). 


\section{Leite Lopes e o Placts}

Esses e outros temas alinham-se sistematicamente com uma forma de pensar a relação entre ciência, tecnologia e sociedade que despontou na segunda metade do século XX e cujos autores integram um grupo denominado - PLACTS. Segundo Dias (2008) - em uma visão partilhada também por Dagnino (2015), e Auler e Delizoicov (2015) - o PLACTS é resultado de um duplo movimento: por um lado foi uma resposta a movimentos sociais que expressavam o descontentamento e a crescente desconfiança da sociedade em relação a distintos problemas, dentre os quais, aqueles ligados à ciência e a tecnologia; por outro lado foi uma resposta da comunidade de pesquisa latino-americana insatisfeita com as recomendações de organismos internacionais como a UNESCO, o BID e a OEA que "apresentavam uma estreita relação com a visão linear da relação entre ciência, tecnologia e desenvolvimento, presente no Relatório Bush" (DIAS, 2008).

Ao mesmo tempo em que se desenvolveu o PLACTS, surgiram outros dois grupos que tinham como objetivo analisar as relações CTS. Dias (2008) resgata essas vertentes:

Como resposta acadêmica à agitação social das décadas de 1960 e 1970 surge, na Europa, a corrente dos Estudos da Ciência e da Tecnologia. Nos EUA, fora da academia surge outra corrente, a CTS. Ambas essas correntes apresentavam como enfoque central uma perspectiva crítica em relação à visão clássica da ciência, essencialista e triunfalista (DIAS, 2008, p. 2).

As preocupações que estavam presentes nos EUA e na Europa também podiam ser encontradas na América Latina, porém com algumas especificidades que acabaram dando forma ao PLACTS. No entanto, a despeito de tais particularidades, "as três vertentes do campo CTS surgem simultaneamente e como resultado da percepção de que a concepção tradicional a respeito da ciência e da tecnologia era insuficiente" (DIAS, 2008). 
Leite Lopes é considerado um dos nomes de destaque entre os autores envolvidos no PLACTS. Assim como ele, os principais autores que são considerados membros do deste grupo tem suas formações originárias nas ciências duras e nas engenharias: Amílcar Herrera, Jorge Sábato e Oscar Varsavsky.

Dias (2008) resgata Kreimer \& Thomas (2004) que caracterizam o PLACTS como pertencentes à segunda de três grandes áreas temáticas existentes dentro dos estudos CTS na América Latino nos anos 1960 e 1970: a abordagem histórica; a abordagem política; e a abordagem sócioantropológica. Da mesma forma, este autor destaca Vaccarezza (2004) que afirma serem alguns dos traços mais marcantes do PLACTS: seu caráter original e autônomo e a sua coerência ao ressaltar a dinâmica estrutural do atraso da América Latina. Finalmente, tem-se a visão de Dagnino et al (1996) que busca destacar o conteúdo político das contribuições do PLACTS.

Algumas das características do pensamento de Leite Lopes que podem ser identificadas com os ideais do PLACTS, que mesmo que não tenha havido um reconhecimento de forma explícita por parte do autor, estão relacionados ao seu entendimento sobre o papel da produção científica na conquista da autonomia e da independência nacional. Conforme destacado, ao perceber a relevância da ciência para o desenvolvimento dos países centrais, Leite Lopes acreditava ser fundamental o fortalecimento da atividade científica nacional para o progresso econômico brasileiro. Essa leitura é fortemente relacionada à forma como o PLACTS entende o enfoque da cadeia linear de inovação, que implica a necessidade de um projeto nacional para a superação dos obstáculos histórico-estruturais impostos pelo subdesenvolvimento (DIAS, 2008).

Assim, para o PLACTS, os elementos relevantes são representados pelos obstáculos estruturais historicamente determinados, tais como a distribuição de renda e as relações de dependência, internas e externas. Dentro da concepção do PLACTS, portanto, para que o modelo da cadeia linear de inovação possa 
se concretizar na prática seria necessária a superação dos obstáculos estruturais relacionados à condição periférica por parte dos países da América Latina (DIAS, 2008, p. 4).

Leite Lopes acreditava que os cientistas devem se preocupar "com o problema da educação básica e não devem ficar em seus castelos de marfim" (CARUSO, 1998, p. 47). Sustentava que era preciso fazer com que fosse despertado nos jovens o gosto pela ciência, por meio, por exemplo, da ida de cientistas e pesquisadores às escolas do ensino médio. Para Leite, essa também era uma missão da universidade pública.

\section{Os Limites do Pensamento de Leite Lopes para o Placts}

Apesar de toda importância que o trabalho de Leite Lopes teve para a construção das instituições para a difusão da ciência que hoje condicionam as estruturas de pesquisa nas universidades e em demais ambientes, é possível identificar em seu pensamento concepções pouco estruturadas acerca de determinados conceitos. Dentre eles, podemos destacar as suas ideias acerca de desenvolvimento econômico e autonomia política, bem como uma interpretação cravejada por uma ideologia "linearista" da ciência e da relação empresa-universidade e produção científica. Tornase assim, fundamental discutir essas perspectivas, uma vez que, os apontamentos aqui realizados acerca do pensamento de Leite Lopes podem ser facilmente direcionados também ao PLACTS.

Ao longo de seu Livro, "Ciência e Libertação", Leite Lopes defende a necessidade de estimular a produção de um modelo de pesquisa e ciência que respeite as particularidades locais que busque responder a demandas e resolver problemas locais, característicos de economias subdesenvolvidas - em um momento de grande crescimento e diversificação tecnológica verificados nas décadas de 60 e 70. Ademais, o autor busca explicitar como o progresso científico não aconteceu de forma homogênea pelo mundo, intensificando as disparidades entre o progresso 
econômico dos países desenvolvidos e os subdesenvolvidos. Em grande medida, o desenvolvimento científico e tecnológico dos países de terceiro mundo estaria em conflito com os interesses e privilégios das tradicionais elites dominantes (LOPES, 1969, p. 14).

A importância em atentar para esse problema naquele momento residia no fato de que, em grande medida, os anos do "Milagre Econômico" caracterizaram-se por uma intensa participação do Estado administrando os investimentos em grandes obras, mas principalmente pelo fato de que se buscava consolidar a indústria de bens de capital no país a partir de maciças importações de bens de elevada complexidade tecnológica. As tecnologias importadas, as quais Leite Lopes é consciente de que foram desenvolvidas em um contexto específico para atender a problemas locais, conformariam toda uma estruturação da indústria nacional e consequentemente poderiam se tornar incompatíveis com as técnicas e a organização socioeconômica regional, atenuando a dependência tecnológica, e a condição de passividade da produção nacional de conhecimento.

A grande maioria dos cientistas e admiradores das nações desenvolvidas, mesmo os mais liberais, continua a sustentar a tese de que aquilo que os países subdesenvolvidos devem fazer é comprar (como em um supermercado) as tecnologias e indústrias necessárias a seu desenvolvimento. Ignoram, assim, que sustentam a manutenção da dependência dos países do Terceiro Mundo em relação aos avançados, dessa vez não mais com vice-governadores ou tropas de ocupação, mas através da dependência mais sutil do conhecimento científico, das tecnologias aperfeiçoadas e, inclusive, de manuais de ensino e métodos de educação, elaborados nas universidades e laboratórios de grandes potências (LOPES, 1969, p. 25).

Em um momento muito específico da industrialização brasileira, Leite Lopes comunga com a ideia de desenvolvimento econômico a partir da consolidação de forças produtivas capitalistas 
por meio da industrialização, um diagnóstico realizado pela CEPAL em meados dos anos 50 , e que governou as políticas das economias regionais desde então. Subentende-se nessa visão, que o processo de globalização, e a vinda de empresas multinacionais aos países em desenvolvimento seria suficiente para alavancar a produção regional de conhecimento científico. Todavia, como os demais autores do PLACTS, ele consegueidentificar a problemática inerente a esse processo industrializador, a construção de uma dependência tecnológica de longo prazo com os países desenvolvidos mascarada de progresso e crescimento econômico. Nesse caso ele observa que, ao longo desse processo houve uma reticencia muito grande das empresas multinacionais em conferir a devida autonomia às subsidiarias nacionais a desenvolver pesquisas e novas tecnologias regionalmente - a partir, por exemplo, da abertura de laboratórios nos países que se estabeleceram - o que deslegitima um projeto industriador para superar a condição de subdesenvolvimento que não se predisponha a mobilizar o aparato científico nacional.

Segundo o autor, a ciência e a tecnologia deveriam ser estimuladas a florescer dentro dos países subdesenvolvidos, em um processo mútuo de cooperação entre empresas multinacionais, universidades e institutos de pesquisa nacionais, mas sempre preservando a autonomia e o poder de decisão nacional. Isso preveniria, por exemplo, a emigração de cientistas e engenheiros nacionais para suprir as necessidades das universidades nas grandes potências. Portanto, para além do papel chave em conduzir o processo industrializador, o Estado teria como principal obrigação, formular e decidir sobre os programas educacionais e institutos científicos, o que garantiria o progresso e a manutenção da soberania nacional (LOPES, 1969, p. 22-25).

A preocupação de Leite Lopes era garantir que o projeto de desenvolvimento incorporasse a dinamização da Ciência e da Tecnologia nacionais, e ao apresentar essas recomendações acerca da organização da disposição da ciência nos países subdesenvolvidos, a todo o momento o autor estabelece uma comparação entre a trajetória de PCT dos países desenvolvidos e a dos países em desenvolvimento. Uma das suas afirmações 
iniciais, o autor considera como principal elemento diferenciador entre países desenvolvidos e em desenvolvimento o fato de que esses primeiros teriam reconhecido de antemão a importância da pesquisa científica para a construção do desenvolvimento econômico e progresso da civilização, e isso teria sido determinante para que esses países se adiantassem na exploração das reservas e riquezas naturais mundiais.

Nesse mesmo espírito, Leite Lopes expõe categoricamente que o desejo dos países de Terceiro Mundo seria "de um desenvolvimento sem perda de identidade nacional, de um desenvolvimento sem perda nem abdicação do poder de decisão, de um desenvolvimento sem imposições, controles nem dominações de caráter neocolonialista" (LOPES, 1969, p. 18). O estímulo à produção científica nacional, seria uma forma de construir uma independência econômica e política nacional, e garantiria um ritmo de progresso tecnológico e civilizacional independente dos ditames das economias centrais, de certa forma, a ciência autônoma aqui, seria sinônimo de liberdade.

Diante dessas concepções de Leite Lopes, muitas das quais são extremamente próximas às do PLACTS - como a ideia de que assumpção de tecnologias importadas, e o não desenvolvimento autônomo da ciência, comprometerem os países latino americanos com uma aliança dependente dos países centrais - é fundamental destacar como elas são válidas para estabelecer uma compreensão crítica acerca dos projetos de desenvolvimento em um determinado período histórico, não dimensionando a complexidade da discussão acerca da relação entre Ciência, Tecnologia e subdesenvolvimento. A consequência disso é o entusiasmo do autor em sugerir projetos para a promoção da educação básica, ciência e tecnologia, os quais necessariamente se traduziriam em inovações que, apropriadas pelas grandes empresas as tornariam mais competitivas, e isso alavancaria o desenvolvimento econômico nacional. Isso ocorre, pois, em vários momentos o autor assume a ciência como um fenômeno neutro em nossa sociedade, além de aceitar uma ideia de "desenvolvimento econômico possível" dentro do engessamento político do capitalismo. 
Assim, é possível estabelecer uma crítica ao pensamento sobre Ciência, Tecnologia e sociedade do autor, em três dimensões: a sua percepção acerca de Ciência, a sua defesa inconsciente de um projeto ofertista-linear acerca da ciência e do desenvolvimento, e finalmente acerca da sua crença em uma superação da condição de subdesenvolvimento dentro das estruturas do capitalismo.

No que concerne à visão de Leite Lopes sobre ciência, destaca-se o fato de ser profundamente arraigado a uma ideia de linearidade da trajetória e neutralidade de seus conteúdos e determinações, o que acaba por comprometer os diagnósticos e propostas de política. Segundo Leite Lopes:

\begin{abstract}
(...) a ciência é neutra - ao menos as chamadas ciências exatas e da natureza - neste sentido que ela não impõe regras sobre como aplicarem-se os resultados encontrados nos laboratórios e gabinetes. A ciência busca a interpretação e correlação dos processos que ocorrem no Universo, em todas as escolas, desde a estrutura cosmológica do espaço físico até a descrição das partículas fundamentais da matéria. Ela procura compreender os mecanismos da vida, a constituição, a origem e a idade dos astros, ela edifica teoremas matemáticos sobre postulados que se bastam a si mesmos em sua coerência lógica e em seu poder de sugestões e intuição criadora (LOPES, 1969, p. 64).
\end{abstract}

Nesse sentido, Lopes expõe a ciência como um fenômeno alheio às pressões políticas, atentando para as características do seu método, a ciência seria uma espécie de prática meramente laboratorial, interpretativa e descritiva da natureza, revelando a sua coerência lógica. Essa visão da ciência como um esforço alheio à política e às relações humanas há muito tempo já foi colocada em xeque, uma vez que as diversas escolas dos estudos sociais da ciência têm cumprido um importante papel de reflexão sobre a forma como atuam os próprios cientistas e como se estrutura o campo científico. A “ousadia” em questionar a separação entre as ciências e a sociedade é uma forma de denunciar àqueles que 
buscam afirmar o ideal de uma ciência pura, e mesmo de defini-la como um projeto social como todos os demais: não mais racional, universal, ou à parte dos problemas mundanos do que qualquer outro (STENGERS, 2002, p. 11). A partir das análises, o cientista estaria sujeito a pressões internas e externas que operam no campo científico, o que desmonta o discurso da blindagem ideológica e da promoção de uma única racionalidade, baseada no discurso da objetividade e do excepcionalismo científico.

A tendência de proclamar a ciência como "senhora da verdade", inatingível pelas críticas, remonta ao século XVII, principalmente os trabalhos de René Descartes, com a consolidação do que pode ser chamado de ciência moderna, algo muito distinto daquela visão romântica da ciência que Lopes apresenta em "Ciência e Libertação". Esse movimento intensificou-se ainda mais com a ascensão do positivismo científico, na primeira metade do século XIX, posição que ganha força especialmente no início do século XX. Segundo Mészáros (2004, p. 245),

Talvez a mais eficaz das maneiras pela qual os compromissos de valor são apresentados com a pretensão de neutralidade e incontestável objetividade seja o apelo à autoridade da ciência, em cujo nome a adoção de certas medidas e cursos de ação é recomendada.

Por um lado, a própria ciência assume diferentes funções de confrontação e rupturas intelectuais e ideológicas. A ascensão da ciência positivista foi essencial para romper com o controle ideológico obscurantista, numa tentativa de emancipação humana aliada ao progresso técnico, já que o controle exercido se mostrava como um freio real aos possíveis desenvolvimentos produtivos à própria razão. A ciência contribuiu enormemente para a prevalência do movimento do Iluminismo sobre os sistemas governamentais absolutistas e para seu próprio desenvolvimento posterior, simbolizado pelas Revoluções Industriais, o que resultou no nascimento de uma relação entre ciência, tecnologia e 
indústria, base para a realização das potencialidades produtivas da sociedade numa escala anteriormente inimaginável (MÉSZÁROS, 2004, p. 246). Por outro lado, a promessa de que a ciência seria capaz de superar as contradições e as desigualdades através de sua disseminação na sociedade, mostrou-se uma falácia, pois a própria lógica do sistema capitalista, construído nas bases iluministas, das revoluções burguesas, é a de apropriação privada, de modo que a produção científica foi cooptada e a ela foram impostos os mesmos imperativos que guiam a busca por valorização do capital nessa lógica para a atividade científica.

Desse modo, não se pode afirmar que a ciência seja um fenômeno neutro. Como Dagnino (2008) e Bourdieu (2004) apresentam, a pesquisa e o "Campo Científico" são espaços profundamente influenciados pelas condições econômicas, pelas virtudes e valores de determinadas elites, pelas condições políticas de um determinado contexto histórico, o que afeta diretamente as orientações e os resultados científicos.

Como uma consequência da sua percepção acerca neutralidade da ciência, Leite Lopes acredita em uma visão ofertistalinear da ciência, algo muito próximo da visão lúdica e oportuna de ciência que se desenvolveu no pós-guerra estadunidense. Com o fim dos conflitos em 1945, os cientistas têm a intenção de dar continuidade à atividade de pesquisa básica, em larga escala, preservando o seu status. Desse modo, fortalecendo essa ideia de promover a pesquisa básica nas universidades, desenvolve-se $\mathrm{o}$ relatório Science the Endless Frontier, elaborado pelo então diretor do Office Defense Research Council, Vannevar Bush, no qual se destaca a pesquisa científica como sendo a base para a edificação de uma economia e sociedade fortes e desenvolvidas e, portanto, à ciência deveria ser dada a mesma atenção durante os períodos de paz que nos períodos de guerra (DIAS \& DAGNINO, 2006). É com base nessa percepção, extremamente conveniente aos interesses hegemônicos dos EUA que se desenvolve uma visão ofertistalinear da ciência, cujo investimento privado e estatal em educação e ciência básica necessariamente se traduziria em inovações tecnológicas, benefícios sociais, e se fortaleceria o projeto de nação. 
Em muito é possível identificar essa percepção no trabalho de Leite Lopes:

(...) O reconhecimento do papel importante da ciência e da tecnologia para o desenvolvimento econômico é recente e é a base da Revolução Científica que se processa nos países superdesenvolvidos; (...) as nações em desenvolvimento independente não podem deixar de adotar, com urgência, um programa de educação básica generalizada, de manutenção e estímulo às universidades e à pesquisa científica e tecnológica, integrado com os planos de expansão econômica e afirmação nacional (LOPES, 1969, p. 26).

Crer que a superação do subdesenvolvimento das nações do "Terceiro Mundo" seria possível, pelo investimento Estatal em educação e ciência, é acreditar que as consequências desse investimento seriam facilmente traduzidas em benefícios coletivos a toda sociedade: manifestos em melhora no nível de renda e homogeneidade do crescimento econômico. Em grande medida, isso não seria um efeito possível de ocorrer em países como os latino-americanos, não apenas por ser um tipo de fenômeno que é pouco observável mesmo nos EUA e em outros países centrais, mas principalmente, como expõem Dias e Dagnino (2006), por não haver uma "cultura de inovação" entre o empresariado nacional e muito menos entre as empresas multinacionais que aqui se estabelecem, como discute o próprio Leite Lopes:

(...) a recusa, por parte das grandes empresas industriais estrangeiras, de abrirem laboratórios de pesquisa nos países do Terceiro Mundo é uma evidência a mais contra qualquer política de ajuda e desenvolvimento desses países, com base na operação de tais companhias privadas (LOPES, 1969, p. 26).

A inexistência de uma cultura de inovação entre o empresariado nacional - algo inclusive verificável nos recentes relatórios da PINTEC-IBGE (Pesquisa de inovação e Tecnologia) - 
contribui para inviabilizar o diagnóstico de que o mero investimento em pesquisa básica resultaria diretamente em um progresso tecnológico com ramificações para a renda e demais melhorias nacionais. No entanto, esse modelo linear-ofertista, como expõe Dias (2009), além de uma consequência do entendimento da ciência como uma prática neutra e dissociada dos seus determinantes políticos, é também uma derivação direta de uma racionalidade nacional-desenvolvimentista, cuja origem remonta à miscigenação entre as elites econômicas e intelectuais, em uma complexa rede de interesses indissociáveis.

Desse modo, os argumentos defendidos por Leite Lopes acerca da organização da PCT em países subdesenvolvidos, apesar de bastante lúcidos quando se trata da influência negativa das trajetórias tecnológicas apropriadas dos países centrais ${ }^{4}$ nos países subdesenvolvidos, fragilizam-se ao desconsiderar as particularidades históricas que inviabilizam o real progresso e desenvolvimento econômico dos países do Terceiro Mundo. Isso porque se ancora em uma visão pouco fundamentada acerca de conceitos de progresso e desenvolvimento, os quais Furtado (1978) ao longo do mesmo período desenvolvimentista discute, e fornece um parâmetro crítico à visão de Leite Lopes.

Como os cientistas, os institutos científicos e as universidades são apoiadas e estimuladas pelo real progresso econômico e social de um país, os resultadose benefícios de suas atividades revertem principalmente de modo natural, para o maior desenvolvimento de tais países (...) Incapazes de obter, adotar e aplicar os resultados das pesquisas científicas em benefício próprio - pois não as praticam - permanecem os

${ }^{4}$ Em diversos momentos de "Ciência e Libertação", Leite Lopes expõe a necessidade de endogenizar um processo de desenvolvimento científico e tecnológico em detrimento da simples importação de processos e dispositivos dos países centrais, algo que produziria, a seu ver uma subutilização dos engenheiros, cientistas e pesquisadores nacionais, algo que resultaria inclusive na "fuga" desses especialistas do país (pg. 30-31). 
povos subdesenvolvidos, e as reservas e riquezas de seus países, à mercê dos povos desenvolvidos, até que forças e condições favoráveis surjam nos primeiros, capazes de estabelecer estruturas adaptadas a um desenvolvimento que tenha significação social e autonomia política, isto é, sem as características, antigas ou modernistas, de dominação e exploração colonial (LOPES, 1969, p 14).

Com isso, Leite Lopes sugere uma correlação entre a debilidade do investimento em pesquisa científica nos países de terceiro mundo, e o adensamento do subdesenvolvimento. Nesse sentido, o conceito de subdesenvolvimento se potencializa a partir da dependência dos países centrais, e a consequente situação de subserviência pelo não desenvolvimento de um aparato de pesquisa cientifica capaz de lançar-nos rumo ao progresso. Por sua vez, a sua interpretação de progresso em muito se relaciona à noção de modernização inerente ao avanço da civilização industrial, ou seja, uma virtual pujança e crescimento econômico que não necessariamente evolua para a distribuição de renda e participação política das massas.

Em Leite Lopes, subdesenvolvimento seria uma etapa econômica a ser superada meramente pelo avanço da ciência e da civilização industrial, cujas benesses se traduziriam em inovações, emprego e renda, novamente um diagnóstico muito próximo do explicitado pela CEPAL nos anos 50. Todavia, ao considerarmos os trabalhos de Celso Furtado, que discutem a fundo a noção de superação do subdesenvolvimento pelo progresso das forças capitalistas como uma ideologia, é possível observar a fragilidade dos argumentos de Leite Lopes acerca dessa percepção.

Buscando compreender as debilidades dos projetos que completariam o ciclo de industrialização no Brasil, Furtado (1978) inicia uma investigação acerca das características mais profundas que marcam o subdesenvolvimento das economias latinoamericanas. De acordo com Furtado (1978), subdesenvolvimento é uma condição histórica aos países de colonização exploratória, e submetidos a um regime agrário exportador complementar ao da metrópole. Essa condição prevalece até hoje, sob aspectos 
muito mais complexos de dominação internas e externas, as quais dificilmente seriam superadas a partir de uma mera política econômica que esteja alheia os determinantes políticos que a fundamentam. Assim, Furtado (1978) identifica, em paralelo a esse contexto um diagnóstico de superação do subdesenvolvimento pela industrialização, a profusão de uma ideologia acerca do progresso e do desenvolvimento, a qual convenientemente é marcada por uma crença na manutenção das estruturas sociais do capitalismo ao mesmo tempo em que supostamente se dissipariam as contradições sociais próprias desse sistema.

Nessa visão, o processo de industrialização e de avanço da civilização ocidental seriam suficientes para superar as contradições sociais, a desigualdade econômica, o atraso tecnológico, a heterogeneidade do crescimento econômico, a dependência estrutural dos países centrais, dentre outras mazelas. Contudo, como ele continua, esse discurso fundamenta-se como uma ideologia bastante sofisticada, no momento em que traveste de progresso o crescimento econômico (acumulação) com diversificação tecnológica, produtiva e do consumo sem, contudo, atentar contra a perpetuação do capitalismo, e de toda a sua estrutura já conhecida de antagonismos sociais: o que permitiria o avanço da acumulação, e apresentaria um horizonte de ascensão social.

Nessas sociedades estruturalmente instáveis, com contradições internas que pareciam condená-las a um fim catastrófico, a ideia de progresso iria constituir a célula mater de um tecido ideológico que serviria de ligadura entre grupos sociais antagônicos. (...) É necessário levá-los [os membros da coletividade] a preferir a estabilidade ao caos, razão pela qual o sufrágio censitário privilegiará por muito tempo aqueles que mais têm a perder com a instabilidade. (...) Acumular interessava, evidentemente, aos grupos que tutelavam a estrutura de poder, mas nem por isso deixava de ser fundamental para todos os grupos sociais que aspiravam aos frutos do progresso (FURTADO, 1978, pps. 100-101). 
Ele continua:

Como não compreender que somente na acumulação poderia ser encontrada solução permanente para os problemas da grande massa da população? Toda tentativa de satisfazer as reinvindicações das massas sem passar por uma intensa acumulação estaria necessariamente condenada a malogro: implicaria desarticulação do sistema econômico, baixa produtividade, desemprego. Acumular interessava, evidentemente, aos grupos que tutelavam a estrutura de poder, mas nem por isso deixava de ser fundamental para todos os grupos sociais que aspiravam aos frutos do progresso (FURTADO, 1978, p. 101).

Furtado (1978) estabelece uma profunda crítica à ideologia do progresso-acumulação, em que o crescimento econômico (ou acumulação) viabilizador de um ideal chulo de progresso, assumiria ares de um projeto econômico nacional fundamental e prioritário a todos, em que virtualmente seriam superados os antagonismos sociais característicos do capitalismo. Evidentemente, a superação não seria real e a ideologia de progresso prolongaria a situação de estabilidade na sociedade, configurando-se como um mecanismo de poder extremamente eficaz à manutenção do poder das elites industriais.

Essa eficácia se deve ao fato de que se mantêm intactos os privilégios das elites nacionais, não explicitados senão sob o aspecto de discursos de poder provenientes de centros hegemônicos, como a universidade. Devidamente legitimada como argumento racional, a ideologia do progresso-acumulação mascara a impossibilidade de um desenvolvimento econômico sem a destituição dos privilégios da elite, e sem a superação da estrutura do capitalismo que não prevê uma maior distribuição de renda.

Em uma breve mediação, a aproximação dessa ideologia de progresso-acumulação do pensamento de Leite Lopes é que reside a fragilidade dos seus argumentos. Pouco se encontra no 
trabalho do autor referências às condições históricas de dominação de uma classe sobre a outra, como os projetos de industrialização nacional refletem os interesses de manutenção dos privilégios de uma classe. Consequentemente, a sua proposta em estimular o investimento nacional em Ciência e educação básica - com a intenção de promover o desenvolvimento industrial e econômico a partir das apropriações desses resultados - se não se fragiliza pelo argumento da passividade do empresariado nacional, desmorona ao ser contraposto à noção de que o subdesenvolvimento é insuperável sem antes se romper as amarras do capitalismo.

\section{Considerações Finais}

Os limites do pensamento de Leite Lopes sobre Ciência e Liberdade encontram-se em não compreender que tanto a ciência como a tecnologia são determinadas socialmente, e em sua gênese catalisam valores e interesses conscientes ou não de classe, que modificam seu uso, e orientam uma determinada conduta ao usuário. A resultante é a profusão em sua obra de argumentos em defesa do desenvolvimento da ciência e da tecnologia em ambiente nacional, acreditando que o rompimento com as amarras estrangeiras seria suficiente para permitir o desenvolvimento econômico e a superação da condição de subdesenvolvimento. Não só o subdesenvolvimento é insuperável dentro das condições do capitalismo e do imperialismo, como também a produção de ciência e tecnologia que de fato acarretaria em uma libertação em relação às formas mais veladas de dominação na sociedade contemporânea.

Apesar das críticas ao pensamento de Leite Lopes acerca da sua concepção de ciência neutra, e de um ofertismo-linear em que o investimento nessas variáveis promoveria inovações, desenvolvimento e libertação, não podemos deixar de admitir a importância de seu pensamento para a conscientização do papel do cientista e da sua responsabilidade para com a sociedade. Nesse sentido, é fundamental expor que mesmo sendo tão discrepante em relação aos demais pensadores do PLACTS, ele foi um 
dos principais responsáveis pelos pilares da política científica e tecnológica em uma economia de industrialização tardia e autoritária, um esforço necessário e pouco destacado ao longo da história.

\section{REFERÊNCIAS}

AULER, D; DELIZOICOV, D. “Investigação de temas CTS no contexto do pensamento latino-americano". Linhas Críticas. V. 21, N. 45, Mai/Ago, 2015.

BOURDIEU, P. Os usos sociais da ciência: Por uma sociologia crítica do campo científico. São Paulo: Editora UNESP, 2004.

CARUSO, F. José Leite Lopes: ideias e paixões. Rio de Janeiro: Centro Brasileiro de Pesquisas Físicas - CBPF, 1999.

DAGNINO, R. Neutralidade da ciência e determinismo tecnológico. Campinas: Editora da Unicamp, 2008.

DAGNINO, R. “O que é o PLACTS (Pensamento Latino-americano em Ciência Tecnologia e Sociedade)?". Ângulo, N. 140, Jan/Mar, 2015.

DIAS, R. B. “Um tributo ao Pensamento Latino-Americano em Ciência, Tecnologia e Sociedade (PLACTS)". Revista Espaço Acadêmico, no 90, Nov. 2008.

DIAS, R. B. Sessenta anos de política científica e tecnológica no Brasil. Campinas: Editora Unicamp, 2012.

DIAS, R. B.; DAGNINO, R. P. “A política de C\&T brasileira: três alternativas de explicação e orientação". Revista Brasileira de Inovação, v. 6, p. 373-403, 2008.

FREIRE JR, O; CLEMENTE, J. E. José Leite Lopes (28/10/191812/06/2006). 2006. Disponível em: <www.fmauriciograbois.org. br/cdm/colecao-principios/150934-44573/2006-06-01/jose-leitelopes-28101918-12062006>. Acessado em: 11/06/2018. 
FURTADO, C. Criatividade e Dependência na civilização industrial. São Paulo: Companhia das Letras, 2008.

LOPES, J. L. Ciência e Libertação. Rio de Janeiro: Paz e Terra, 1969. MARCOLIN, N. “Movido a Paixões: José Leite Lopes, morto aos 87 anos, deixa vasto leque de realizações". Revista Pesquisa FAPESP, Ed. 125, Jul. 2006.

MÉSZAROS, I. O Poder da Ideologia. São Paulo: Boitempo, 2004.

MORIN, E. Ciência com consciência. Tradução de Maria D. Alexandre e Maria Alice Sampaio Dória. $8^{\underline{a}}$ ed. Rio de Janeiro: Bertrand Brasil, 2005.

STENGERS, I. A Invenção das Ciências Modernas. São Paulo: Editora 34, 2002.

STOKES, D.E. O quadrante de Pasteur: a ciência básica e a inovação tecnológica. Campinas: Ed. UNICAMP, 2005. 
